\title{
Library Usage Habits of First- and Second-year Medical Students at a Satellite Campus: Report on an Exploratory Questionnaire ${ }^{1}$
}

\author{
Jackie Phinney
}

\begin{abstract}
Introduction: Anticipating the information needs of undergraduate medical students can be challenging, especially within the context of distributed medical education at a satellite campus. The purpose of this study was to evaluate how first- and second-year medical students in the Dalhousie Medicine New Brunswick program are using their satellite campus' library services and if they would prefer to use their home institution's electronic collection as opposed to print collections from the satellite campus library. Methods: First- and second-year medical students were asked to complete a paper survey towards the end of their academic year, which focused on background information, study habits, access preferences and tendencies (print book vs. electronic), satisfaction with their physical library space and collection, as well as their likelihood of completing required course readings. Results: Although both groups actually used electronic books more than print, the first-year class stated a preference for print books. Overall students were satisfied with their physical library's services, but were less likely to borrow a book if it is on course reserve. Discussion and Conclusions: When providing library services to undergraduate medical students, it is important to note that their opinions and needs can evolve quickly and be unpredictable. Librarians should consider maintaining a print collection while transitioning to electronic, in keeping with the trends of academic health librarianship.
\end{abstract}

\section{Introduction}

According to the Association of Faculties of Medicine of Canada, "satellite campuses are commonly referred to as regional campuses and can be situated relatively close to the parent university or at a considerable distance" [1]. In September 2010, the Dalhousie University Faculty of Medicine welcomed its first class to the Dalhousie Medicine New Brunswick (DMNB) satellite campus, located at the University of New Brunswick Saint John (UNBSJ). While attending DMNB, approximately 30 students in each year spend the first two years of the undergraduate curriculum in the classroom and clinical skills settings with Dalhousie-appointed instructors, whereas the last two years are spent throughout the province on distributed clerkship rotations.

Because of the distance between campuses, all efforts have been made to ensure that the Dalhousie Medicine campus in Halifax and the Saint John satellite campus remain comparable, and guaranteeing library services is no exception. In Saint John, the print medical collection is housed at the UNBSJ campus library; the Hans W. Klohn Commons (HWK Commons). This includes all titles designated as reference, reserve, or allocated to the main collection. One librarian, who monitors the collection at the Halifax campus and ensures that the two are comparable, oversees the collection in Saint John. Students access their electronic materials via the Dalhousie Libraries web site using WorldCat catalogue or Novanet (a consortium of Nova Scotia institutional libraries), but they also retain access to all of the University of New Brunswick's electronic and print items via WorldCat should they wish to use them. Although the librarians at both campuses recognize the value of electronic access, not all course materials are currently available in this format.

Circulation reports of the print reserve collection at the UNBSJ campus library have demonstrated low usage statistics since the program's implementation, with one such example being a print-only textbook for the Foundations 1 unit that had four charges since being added to the collection in 2011.

As user preferences and habits continue to evolve, recent literature on medical students' information use indicates mixed preferences for print versus electronic books. Lasserre et al. surveyed Australian medical students on their information use and found that $59 \%$ of the respon-

Jackie Phinney. ${ }^{2}$ Information Services Librarian, University of New Brunswick Saint John, Hans W. Klohn Commons, 100 Tucker Park Road, Saint John, NB, Canada E2L 4L5.

${ }^{1}$ This paper is peer reviewed.

${ }^{2}$ Corresponding author (e-mail: j.phinney@unb.ca). 
dents across all years preferred print over electronic [2]. Hartel and Cheek made a similar discovery in surveying medical students, staff, and faculty in an academic medical centre, with the results showing that print format of books was most popular when compared with web-based books and e-books pre-installed on a device [3]. They also found that "participants noted frustrations adapting to different [e-book] provider platforms and stated a desire to have both print and web-based books available". However, participants also noted that they prefer using print books when reading large amounts of text but carrying large books is an inconvenience.

Such findings would suggest that the usage statistics of the UNBSJ campus library's reserve collection should be higher for the DMNB students, particularly given the close proximity of the DMNB building to the HWK Commons building (directly next door). Therefore, in considering the UNBSJ library's statistical evidence as well as the electronic book collection available to the students through Dalhousie, the librarian decided to investigate the students' library usage, in particular their preferences versus habits in using print and electronic textbooks. In conducting this project, the librarian did not seek to prove a hypothesis. Instead, what began as an exploratory project provided some interesting findings that can speak to health librarianship and its role in the provision of services to medical students.

\section{Methods}

A paper survey containing 10 multiple-choice questions (with an 11th question for those who answered "true" to question 10) was drafted by the librarian as well as a letter explaining the purpose of the project. Questions were closed-ended, but two questions allowed space for students to explain their choice in answering "other". The survey was administered on paper and in person to ensure a higher response rate within a small sample, as the librarian acknowledged the students' high volume of universityrelated email and anticipated fewer replies to an online survey. The targeted respondents were the entire first- and second-year classes at DMNB (Med 1 and Med 2; $n=60$ students). The third-year class was on clerkships throughout the province for eight months at the time of the survey; therefore, it was predicted that their use of the library would be remarkably different from the students still completing lecture-based coursework in Saint John.

Addressing different factors that may be influencing book access was key; therefore, the questions began by asking background information on the student, which progressed into questions about their study habits such as the average number of hours per week spent on schoolwork and their preferred location to study. The remainder of the survey focused on areas such as their preference and tendencies when choosing print versus electronic books, and if they found the UNBSJ library easy to use (and were likely to borrow a book if it is on reserve). Students were also asked if they had encountered a time when they needed a book and neither Dalhousie nor UNBSJ libraries had it, and if so, how often has this happened as well as the likelihood of completing required readings (see Appendix
A for the survey). The survey and letter were submitted to the University of New Brunswick Saint John's Research Ethics Board and were approved by them as well as Dalhousie University.

First- and second-year DMNB students were notified prior to their weekly group tutorial sessions that their librarian would be visiting them with a short survey. The librarian arrived in advance of the sessions and solicited the help of the four session tutors in distributing the surveys and letters. The librarian tabulated answers using Microsoft Excel and percentage values were calculated. It was not anticipated that students would include handwritten notes on their survey papers, but some students did. These comments were also taken into account in the analysis, as such notes provided additional insight when interpreting the results.

\section{Results}

Twenty-nine students in the first-year class were asked to respond to the survey, and 28 completed surveys were returned (one student left quickly at the end of the tutorial session). Thirty-one students in the second-year class were targeted and all participated. All data came from the survey results, which have been reported according to content themes with corresponding question numbers:

\section{Background information (questions 1 and 2)}

All respondents in the Med 1 class $(n=28)$ and in the Med 2 class $(n=31)$, reported their year correctly. The majority of students in both classes possessed a Bachelor's degree before entering medical school, some held a Master's degree and one Med 1 student had earned a Doctorate (Table 1).

\section{Study habits and preferred location (questions 3 and 4)}

Students were asked to indicate the number of hours spent on coursework each week outside of scheduled class time. In the Med 1 group, the same number of students selected $9-12$ hours $(39 \% ; n=11)$ and 13 or more hours $(39 \% ; n=11)$. Within this group, most students $(71 \%$; $n=20$ ) stated a preference for studying at home (Table 2). No Med 1 students reported studying at the hospital next door or selected "other", but one student wrote a note stating that they preferred the DMNB building more than home and another specified the exact location in the library where they studied (quiet reading room). Some students chose more than one answer for this question, thereby skewing the percentage values.

Of the Med 2 group, most students indicated high numbers of extra time spent on coursework, with $39 \%$ $(n=12)$ choosing $9-12$ hours, and $51 \%(n=16)$ selecting 13 or more hours. Of the Med 2 students, $71 \%(n=22)$

Table 1. Background information of respondents.

\begin{tabular}{lcc}
\hline $\begin{array}{l}\text { Education achieved before } \\
\text { medical school (question 2) }\end{array}$ & $\begin{array}{c}\text { Med 1 } \\
(n=28)\end{array}$ & $\begin{array}{c}\text { Med 2 } \\
(n=31)\end{array}$ \\
\hline Bachelor's degree & $75 \%(n=21)$ & $84 \%(n=26)$ \\
Master's degree & $21 \%(n=6)$ & $16 \%(n=5)$ \\
Doctoral degree & $4 \%(n=1)$ & $0 \%(n=0)$ \\
\hline
\end{tabular}


preferred to study at home (Table 2). As with the first-year class, no one selected "other" and some students offered more than one answer.

\section{Access preferences and tendencies (questions 5 and 7)}

Students were asked to indicate how they prefer to access books for coursework as well as to check all that apply for how they actually do so (Table 3). In the Med 1 class, $10 \%(n=3)$ indicated their access tendencies with "other", and they described using journal articles, the Internet, or not having accessed a book at all. The Med 2 data also included "other" $(n=2)$, specifically other books online or students sharing PDF versions of books. One Med 2 student also included a note saying that the library's two-hour reserve period is insufficient.

When given the choice between electronic or print books, one of the Med 1 students gave a supplementary answer stating that "PDFs are just better" and chose neither of the given options as an answer.

\section{Library ease of use and borrowing reserve items (questions 6 and 9)}

The survey respondents were asked how easy it is to locate and (or) borrow books from the UNBSJ library, including the likelihood that they will borrow something if it is on course reserve (Table 4). Both Med 1 and Med 2 indicated that it is easy to locate and (or) borrow books, although $18 \%(n=5)$ of the Med 1 class deemed this

Table 2. Study habits (number of extra hours spent on coursework) and preferred location to study.

\begin{tabular}{lcc}
\hline Question & Med $1(n=28)$ & Med $2(n=31)$ \\
\hline Number of extra hours spent on coursework (question 3) \\
1-4 hours & $4 \%(n=1)$ & $0 \%(n=0)$ \\
$5-8$ hours & $18 \%(n=5)$ & $10 \%(n=3)$ \\
9-12 hours & $39 \%(n=11)$ & $39 \%(n=12)$ \\
13 or more hours & $39 \%(n=11)$ & $51 \%(n=16)$ \\
Preferred location to study* (question 4$)$ & \\
Home & $71 \%(n=20)$ & $71 \%(n=22)$ \\
DMNB building at UNBSJ & $18 \%(n=5)$ & $23 \%(n=7)$ \\
$\quad$ campus & & \\
UNBSJ's library & $25 \%(n=7)$ & $3 \%(n=1)$ \\
Hospital & $0 \%(n=0)$ & $10 \%(n=3)$ \\
Other & $0 \%(n=0)$ & $0 \%(n=0)$ \\
\hline
\end{tabular}

*Values do not equal $100 \%$

Table 3. Access preferences and tendencies of course textbooks.

\begin{tabular}{lcc}
\hline Question & Med 1 $(n=28)$ & Med 2 $(n=31)$ \\
\hline Book access preference (question 7) & \\
E-book & $43 \%(n=12)$ & $65 \%(n=20)$ \\
Print copy & $54 \%(n=15)$ & $35 \%(n=11)$ \\
Supplementary & $3 \%(n=1)$ & $0 \%(n=0)$ \\
Book access actual* (question 5$)$ & \\
E-book through Dalhousie & $89 \%(n=25)$ & $97 \%(n=30)$ \\
In person through UNBSJ & $21 \%(n=6)$ & $13 \%(n=4)$ \\
Purchased books & $46 \%(n=13)$ & $64 \%(n=20)$ \\
Hospital library & $0 \%(n=0)$ & $10 \%(n=3)$ \\
Other & $10 \%(n=3)$ & $6 \%(n=2)$ \\
\hline
\end{tabular}

question "not applicable" or in one student's response, "don't do". Of the Med 2 class, 19\% $(n=6)$ felt that this question was "not applicable". These answers were not given as an option, and students chose to write this on their survey instead of answering "true" or "false".

Students expressed their likelihood of borrowing a book if it is on course reserve, with one Med 2 student stating that "either way I probably wouldn't bother" when given a choice between "true" or "false". In the Med 1 group, one respondent left this question blank.

\section{Collection satisfaction (question 10)}

When asked to answer "true" or "false" to encountering a time when a book was needed for coursework and neither Dalhousie nor UNBSJ's library had it, over half of the students answered "true" (Table 5). Of this group, most students (Med $1=56 \%$; Med $2=75 \%$ ) indicated that this has only happened "a few times".

\section{Required readings (question 8)}

When asked to indicate the likelihood of completing a required reading, both classes answered "sometimes" as the majority response (Med $1=75 \%$; Med $2=61 \%$ ), while a minority do the required readings "always" (Med $1=21 \%$; Med $2=39 \%$ ). Only one of the Med 1 students reported "never" doing required readings, and none of the Med 2 class reported this.

\section{Discussion}

The purpose of this study was to investigate how the Med 1 and 2 students at DMNB's satellite campus are using their physical library services, and if they would prefer accessing course textbooks electronically through

Table 4. Library ease of use and borrowing reserve items from the library.

\begin{tabular}{lcc}
\hline Question & Med 1 $(n=28)$ & Med 2 $(n=31)$ \\
\hline UNBSJ library ease of use (question 6) & \\
True & $53 \%(n=15)$ & $58 \%(n=18)$ \\
False & $29 \%(n=8)$ & $23 \%(n=7)$ \\
Supplementary n/a & $18 \%(n=5)$ & $19 \%(n=6)$ \\
Less likely to borrow a reserve item (question 9$)$ & \\
True & $46 \%(n=13)$ & $65 \%(n=20)$ \\
False & $50 \%(n=14)$ & $32 \%(n=10)$ \\
Supplementary & $0 \%(n=0)$ & $3 \%(n=1)$ \\
Left blank & $4 \%(n=1)$ & $0 \%(n=0)$ \\
\hline
\end{tabular}

Table 5. Collection satisfaction with either institution

\begin{tabular}{lcc}
\hline Question & Med 1 $(n=28)$ & Med 2 $(n=31)$ \\
\hline $\begin{array}{l}\text { Needed a book and neither Dalhousie nor UNBSJ had it } \\
\quad \text { question 10) }\end{array}$ & $52 \%(n=16)$ \\
True & $64 \%(n=18)$ & $48 \%(n=15)$ \\
False & $36 \%(n=10)$ & \\
If "true", how often? & & $19 \%(n=3)$ \\
Only once & $44 \%(n=8)$ & $75 \%(n=12)$ \\
A few times & $56 \%(n=10)$ & $6 \%(n=1)$ \\
Happens a lot & $0 \%(n=0)$ & \\
\hline
\end{tabular}


the Dalhousie Library's web site versus in print format at their satellite campus library. This study did not seek to prove a hypothesis and was intended as an evaluation of library usage since the program's recent implementation. However, noteworthy findings did emerge from the returned questionnaires and are represented here by class.

The Med 1 class demonstrated that their preferences did not match their actual tendencies, as the results showed that they would rather use a print book when in actuality they are not. This was surprising considering the timing of the survey and the number of months $(n=8)$ that would have allowed them to find their study style. However, other results indicated that it may just be a strict schedule combined with convenience. The majority of students indicated that they preferred studying at home, so although it would be ideal to have the print version of a book it may not always be a readily available option for them. This could also be affected by the library reserve policies in place, as it was noted through supplementary commentary that the two-hour loan period is insufficient. When evaluating the UNBSJ library's services, the Med 1 data indicated that most students found the library easy to use. Therefore, when pairing these results with the data showing that the majority of students were only "sometimes" doing their required readings, one might argue that their busy schedules are influencing the prioritization of their time and checking out their textbooks may not be of great importance to them, especially if they think the readings may be available online.

The data from the Med 2 class suggest alternate opinions, as students indicated that overall they preferred electronic books and were using them accordingly. This could explain why a large number were less likely to borrow a book if it is on course reserve, and it also offers a correlation with the majority preferring to study at home. As with the Med 1 class, over half of the Med 2 class indicated that they only "sometimes" do their required readings, which could again be attributed to their demanding schedules. When comparing the two classes, the data also suggest that the Med 2 students may have solidified their study style by this point in their medical training, as they preferred electronic versions of the material and outright admitted to doing so. However, there could also be cohort or curricular differences between Med 1 and 2 that were unaccounted for in the survey, thereby indicating a weakness in this study.

\section{Moving forward}

Although somewhat perplexing and rather inconclusive, the data obtained from this survey demonstrate the changing nature of the medical library. The results highlight the difficulty in making solid predictions about provision of library collections for undergraduate medical students at a satellite campus, and it leads librarians to wonder how to serve these students who are between the worlds of books in print versus electronic. It is important to evolve with the educational methodologies used in the undergraduate medical curriculum, but librarians should keep in mind that print collections are still valuable to some students and therefore should be maintained to some degree. Fyfe et al. mentioned this in their discussion of distributed medical education in British Columbia, stating that some students still prefer print, Internet access is not always reliable and not all desired materials are currently available online [4]. They also presented a somewhat similar view as Hartel and Cheek in stating that "not all platforms are desirable, and remote authentication to licensed resources continues to prove challenging" [4]. Therefore, within the context of distributed medical education, print books should still be in place to provide additional support if necessary.

One must also consider the broader picture though, which is that these medical students will soon be practising physicians who will be constantly consulting information resources. With electronic book providers at their fingertips, will they consult their library's print collection for information that is already contained on their varying devices? Pairing this with the falling prices of tablet computers, health sciences libraries will need to take this into consideration when planning the collection. Returning to Hartel and Cheek's study, the idea that large books are inconvenient resonates with the idea that electronic options are perhaps just easier to handle. A study by Folb et al. reiterated the possibility of the print medical collection as redundant to professionals, as they surveyed all patron groups of an academic health sciences library that serves both University of Pittsburgh and health system affiliated patrons [5]. They found that over $70 \%$ of respondents in the categories of "attending physicians", "interns, residents, or fellow" and "postdoctoral or fellows" reported using electronic books. It was also found that overall, all respondents reported using the library's website more than the physical library to answer health sciences related questions.

Previous literature presents differing views, and this study yielded puzzling data on what medical students think versus how they are actually behaving. A major weakness of this exploration was that the survey was closed ended. This made it difficult to draw solid conclusions based on simple multiple-choice questions and created the possibility that the wording was confusing (i.e., question 7 could be interpreted as asking about a tendency, not a preference). The students also chose to provide extra input through handwritten notes, and they should have the chance to give more original answers in subsequent surveys. In the future it would also be beneficial to ask which subject areas they choose to purchase their books for. Understanding what they deem important enough to buy would help the librarian make decisions about collections management and loan policies. A question about which devices students are using to access e-books would also aid in collections and service planning. Tablet devices are becoming increasingly popular among students, and these offer a potentially better reading experience than a phone, PC, or laptop computer. Finally, future surveys of students in this program should also incorporate the distributed clerkship students, so that information usage habits can be tracked within the clinical setting, thereby mimicking how they may one day use information as practising physicians.

For now, library staff working with the DMNB program will continue monitoring the collections and attempt to predict how best to meet the needs of students within the 
rapidly changing and somewhat unpredictable realm of medical education.

\section{Acknowledgements}

The author would like to thank the staff and students of the DMNB program for their assistance in conducting this research.

\section{References}

1. The Association of Faculties of Medicine of Canada (AFMC). Mapping undergraduate distributed medical education in Canada. [Internet] Ottawa; 2010. [Accessed 29 August 2013]. http://www.afmc.ca/pdf/Mapping_Undergraduate_Distributed_ Medical_Education_in_Canada_Oct2010_Eng.pdf.
2. Lasserre KE, Foxlee N, Kruesi L, Walters J. Health sciences librarians' research on medical students' use of information for their studies at the medical school, University of Queensland, Australia. Med Ref Serv Q. 2011;30(2):141-57. doi: 10.1080/ 02763869.2011.562794.

3. Hartel LJ, Cheek F. Preferred book formats in an academic medical center. Journal of the Medical Library Association: JMLA. 2011;99(4):313-17. doi: 10.3163/1536-5050.99.4.011.

4. Fyfe T, McDavid K, Raworth R, Snadden D. Medical education distribution in British Columbia: A thriving partnership. JCHLA. 2009;30(2):47-9. doi: 10.5596/c09-015.

5. Folb B, Wessel C, Czechowski L. Clinical and academic use of electronic and print books: The Health Sciences Library System e-book study at the University of Pittsburgh. J Med Libr Assoc. 2011;99(3):218-28. doi: 10.3163/1536-5050.99.3.009.

\section{Appendix A: Library Survey - Dalhousie Medicine New Brunswick}

1. My current status as a DMNB student is:
a) Med 1
b) Med 2
c) Med 3
d) Med 4

2. Before studying at DMNB, my highest degree obtained was a:

a) Bachelor's degree

b) Master's degree

c) Doctorate

3. On average, I spend the following number of hours on schoolwork each week (outside of classes, clerkship, etc).
a) $1-4$
b) $5-8$
c) $9-12$
d) $13+$

4. My preferred location to study is:
a) Home
b) DMNB building on UNB Saint John campus
c) HWK Commons
d) Hospital
e) Other

5. When needed for coursework, I access books in the following way(s) (check all that apply).

a) As an E-book through Dalhousie Libraries

b) In person from the HWK Commons

c) I've purchased my books

d) Hospital library

e) Other

6. I find it easy to locate and borrow books from the HWK Commons.

True

False

7. If given the choice between using an E-book or print copy, I would choose.

a) E-book

b) Print copy 
8. When given a required reading for a course, I will do the reading (pick one).
a) Always
b) Sometimes

c) Never

9. If a book is on reserve at the library, I am less likely to borrow it.

True

False

10. I have encountered a time when I wanted a book to help me with coursework, and neither Dalhousie Libraries nor the HWK Commons had this book.

True

False

If you answered 'True', how many times has this happened to you?

a) Only once

b) A few times

c) It happens to me a lot

Thank you very much for your time! 